\title{
Using Digital Games to Learn Mathematics - What students think?
}

\author{
Su Ting Yong ${ }^{1}$, Ian Harrison², Peter Gates ${ }^{2}$ \\ ${ }^{1}$ The University of Nottingham Malaysia Campus, Su-Ting.Yong@nottingham.edu.my \\ ${ }^{2}$ The University of Nottingham, \{lanHarrison, PeterGates\}@nottingham.ac.uk
}

\begin{abstract}
The aim of this study was to explore how university foundation students perceive the use of digital games in learning mathematics. Data was collected using an online questionnaire and 209 foundation university students participated in this study. The questionnaire was used to explore students' gaming experience and students' attitude towards mathematics learning with digital games. It was found that most of the university foundation students liked to play different types of digital games. Males preferred playing digital games in more traditional male genres namely sport, racing, shooter, action adventure, role play and strategy games. As for females, they generally preferred playing puzzle and simulation games. Astonishingly, the foundation students were not very positive towards the use of digital games in learning mathematics, and their attitude was essentially influenced by their mathematics interest. Students with greater interest in mathematics were more likely to support the use of digital games in learning.
\end{abstract}

Keywords: mathematics, digital games, gender, course, attitude;

\section{Introduction}

Rapid advancement of computer technologies offers the development of new approaches in teaching and learning. Computer usage in mathematics education typically includes on-line learning, on-line forums and discussion boards, statistical tools, educational games, Excel, Matlab, etc. Mathematics has been a highly respected discipline in education for centuries. Student success in mathematics is extremely important in many fields of study including engineering, science, business and computer science. Moreover, "proficiency in mathematics is a strong predictor of positive outcomes for young adults, influencing their ability to participate in postsecondary education and their expected future earnings" [1, p. 6]. Digital games such as video games, computer games and other electronic games offer a tremendous opportunity for learning mathematics since students who are normally uninterested in mathematics, surprisingly, stay on task in games that required tedious computations and problem solving [2]. Consequently, games may help students to associate enjoyable gaming experiences to mathematics learning, and this could help students to develop a deeper interest in mathematics [3]. Over the past few years, issues related to introduction of technologies for the teaching and learning of mathematics have been the subject significant research and this has been accompanied by research on students' affective (attitudes and beliefs) towards mathematics. Affect is a research interest in mathematics education as the students' attitudes and beliefs towards mathematics are strongly related to their success in mathematics [4]. Prior to deployment of computer games for mathematics education at university level, ascertaining students' perceptions and views is important for any successful implementation. This study aims to investigate students' views and attitudes towards use of digital games in learning mathematics at university foundation level. 


\section{Review of Literature}

\subsection{Affective}

The affective domain is conceptualized by belief, attitude and emotion and it plays a central role in mathematics learning. For students to become active learners, willing to tackle non-routine problems, their response in the affective domain needs to be higher than students who perform low-level routine mathematical operations [5]. A student's belief is developed over a relative long period of time and is largely cognitive [5] being learnt from experience. A student having prolonged negative experience at solving mathematical problems will lead eventually to a poor belief in one's own capabilities, whilst a positive experience will produce a more confident belief. On the other hand, emotions involve little cognitive appraisal and are short term in nature. There will be frustration at the inability to solve a problem, followed by joy when a solution is found [5].

Attitude cannot be defined easily [6] but a long-term positive or negative emotional disposition towards mathematics will affect a student's attitude to mathematics [7]. A series of experiences will definitely promote a positive or negative attitude contributing to the development of more persistent attitudes or beliefs that may influence the future behaviour [6]. In general, belief is developed over a long period of time, is relatively stable and not easily changed, but attitude is moderate in duration, intensity and stability and it has an emotional content. Thus, beliefs and attitudes are generally stable but emotions may change rapidly. This study focused on students' attitude, which is the long-term positive or negative emotional disposition, towards learning mathematics with digital games. Teaching of mathematics using digital games requires a pedagogical shift and changes in the learning environment. The learning environment plays a significant role in the enjoyment of mathematics learning because it influences students' affective responses [8].

\subsection{Attitude towards Mathematics Learning with Technology}

Research has indicated that students' attitude towards learning mathematics with technology is greatly influenced by their attitude towards the subject itself and technology in general. For instance, students are more likely to have a positive attitude towards the use of computers in learning mathematics if they rated themselves highly in computer proficiency [9] and achieved good performance in mathematics [10]. Hence, any study of students' attitude towards learning mathematics with technology would need to incorporate an analysis of their attitude towards the subject as well as attitude towards technology.

In past research, students who were exposed to mathematics educational software showed a more positive attitude towards mathematics and computer assisted learning [11] and most students also did agree that it was better to learn mathematics with technology [6]. Students' positive attitude towards learning mathematics with computers was linked to their mathematics confidence and how they feel about mathematics [10]. Gender differences showed that boys were more positive towards use of technology in learning mathematics compared to girls [9], [10]. Boys were more likely to believe that computers contributed to their pleasurable experience in mathematics simply because technology was present, but for girls, they were more concerned about whether computers facilitated learning and enabled them to succeed in mathematics [6], [9]. Pierce et al. [6] found that for boys, attitude to learning mathematics with technology was positively correlated with confidence in using technology but for girls, it was negatively correlated with mathematics confidence. Computer technology has offered interesting potential new methods to aid teaching and learning through cognitive, metacognitive and affective channels and monitoring students' attitude is significantly crucial [6]. Positive attitudes toward mathematics has been claimed to strongly increase students' achievement in mathematics, conversely, a negative attitude towards mathematics has caused the failure to learn appropriate mathematical skills [4], [12]. Therefore, a positive attitude towards use of computer technologies in learning mathematics may improve students' mathematics achievement and vice versa.

\subsection{Digital Games in Educational Use}

According to Van Eck [13], there are three approaches to integration of digital games into teaching and learning, namely (i) use of educational games; (ii) use of commercial off-the-shelf (COTS) games and (iii) game development. The first approach was the focus of this study in which 
students were asked for their views and opinions on the possibility that educational games were seamlessly integrated into learning. Based on this approach, game play is used to address educational and entertainment equally; learning while playing [13]. Educational games have gone through a series of development from the first generation of edutainments that were built on drill and practice [14], until today's educational computer games that are built on learning through gameplay experience [15]. Educational games have been developed to learn mathematics in many past studies, for instance Astra Eagle in [16], Triangle in [17], Magalu, Hermes, Tiki-Tiki and Roli in [18], Proportional Tetris and Proportional Clown in [19]. Though students are generally positive towards learning with technologies, their attitude could be influenced by their attitude towards the subjects and their technology proficiency [6], [9]. Thus, the studies conducted in Australasia [9] and Australia [6] could be replicated in Malaysia to investigate whether students' attitude towards use of educational games in learning mathematics are influenced by students' technology confidence and attitude towards mathematics.

\section{Aims of the Study}

The aims of this study were:

1. To investigate students' gaming experience.

2. To investigate students' views and opinions towards mathematics.

3. To investigate students' views and opinions in using digital game for learning mathematics.

4. To investigate similarities and differences in the views expressed by male and female students.

5. To investigate similarities and differences in the views expressed by engineering, science and social science students.

\section{Research Method}

\subsection{Sample}

The participants were 209 foundation year students studying at a higher institution in Malaysia. The entry level into the foundation year programmes is after 11 years of schooling and majority of the students had just taken the Malaysian Certificate of Education qualification. The students were studying on the engineering, science or business/arts (i.e. social science) foundation programmes. The sample of the study was selected based on convenience sampling defined as where "people who are available, volunteer, or can be easily recruited are included in the sample... individuals who can be conveniently selected" [20, p. 238]. In addition, participants were readily available to us [21]. In fact, the majority and most commonly used sampling method for quantitative give research is convenience sampling [20], [21] because most of the time, it is extremely difficult to select either a random or a systematic non-random sample [22]. In this study, convenience sampling was employed and students' participation was based on voluntary basis. We do not feel this strategy poses any threats to validity or overall research quality.

\subsection{Instrument}

Data on attitudes can be collected via a variety of different methods (e.g. documentary, interview or questionnaire) but no approach has been found to be superior over any other. Asking students to pause and reflect briefly before providing answers to the questionnaire can provide data which would not be obvious through observation [6]. The alternative of interviewing every student would be time consuming [6]. The Mathematics and Technology Attitudes Scale (MTAS) developed by Pierce et al. [6] was used in this study to assess the role of the affective domain in learning mathematics with the use of technology. This self-reported instrument can be used in classrooms by either researchers or teachers to track changes in the attitudes and engagement of students in their learning of mathematics in response to the introduction of new technology in to the learning environment. The instrument consists of 20 questions which measures the following attributes: (1) mathematics confidence [MC], (2) affective engagement [AE], (3) behavioural engagement [BE], (4) confidence in using technology [TC] and (5) attitude to the use of technology to learn mathematics $[\mathrm{MT}]$. The MT items can be modified and adapted to determine the attitudes to learning with other technologies used in the class [6]. In this study, MT items were 
modified to MTg to denote digital games. A five-point Likert scale from strongly disagree to strongly agree (scored from 1 to 5) were used for each subscales: MC, TC, AE and MTg. However, a different Likert scale was used for BE subscale - hardly ever, occasionally, about half of the time, usually, nearly always (scored from 1 to 5). The subscales of the MTAS scale were defined by Pierce et al. [6] as follows:

- Mathematics confidence [MC]: students' perception of their ability to attain good results and their assurance that they can handle difficulties in mathematics.

- Affective engagement [AE]: how students feel about mathematics.

- Behavioural engagement [BE]: how students behave in learning mathematics.

- Confidence with technology [TC]: "feel self-assured in operating computers, believe they can master computer procedures required of them, are more sure of their answers when supported by a computer, and in cases of mistakes in computer work are confident of resolving the problem themselves" [23, p. 278].

- Attitude to learning mathematics with digital games [MTg]: this subscale is modified to measure the degree to which students perceive that the use of digital games in mathematics provides relevance for mathematics, aids their learning of mathematics and contributes to their achievement in mathematics.

The MTAS questionnaire can be administered within 10 to 15 minutes and a value for each subscale can be obtained by adding the responses from all four related items [6]. In this study, questionnaires used consisted of MTAS instrument and gaming experience questions. Thus, students took about 30 minutes to complete the questionnaires. Since the Likert scale for each question is scored 1 to 5 , each subscale has a minimum score of 4 and a maximum of 20 . Following the work of Pierce et al. [6], a score of 17 or above was defined to reflect high and a very positive attitude towards the factor being measured, 13 to 16 suggested a moderately high attitude, and 12 or below indicated low score which was indicative of a neutral or negative attitude; we adopted this approach. MTAS encompasses of both feelings and opinions about doing and learning of mathematics, and this instrument can give some indications of what variables contribute or do not contribute to students' evaluation of the effectiveness of learning mathematics with digital games.

\subsection{Data Collection}

Data was collected from July 2013 to March 2014. The questionnaire was available online and students were briefed by the first author that the purpose of the study; was to obtain demographic information, gaming experience, attitudes towards mathematics and use of digital game in learning mathematics lesson. Digital games in this study were defined as any computer game, video game or other electronic game and to communicate this operationalization, students were given some examples of online digital games at the following links:

- http://www.mathplayground.com/games.html

- http://www.coolmath-games.com/

- http://www.mathsisfun.com/games/

- http://www.primarygames.com/math.php

Though all the examples given may not be suitable for university level, the online digital games we hoped would give an idea to the students of what the mathematics educational games looked like. Since digital games were not used for teaching mathematics in the students' university foundation level courses, this was a preliminary study to determine students' attitude towards a potential use of digital game in learning mathematics. The students were asked of their opinion and views as indications of what variables contribute or do not contribute to students' evaluation of the effectiveness of mathematics learning with digital games. The students did play the educational games as stated above. However, they had no exposure to mathematics computer games in a formal classroom setting. This study was meant to explore the potential use of digital games in mathematics learning for future attempt. Therefore, the students were giving their opinions based on their theoretical knowledge and scenarios. 


\section{Data Analysis}

\subsection{Demographic Data}

In total, 209 university foundation students responded to this survey. The frequency distribution of the respondents is given in Table 1. Demographic data collected includes gender and course of study. The response rate from social science and science students was about $99 \%$. Unfortunately, the response rate from engineering students was about $47 \%$. Students' participation was on voluntary basis and no coercion was used. Though the response rate was not high for engineering students, Wallace as cited in [24] argued that the results were still drawn from a random sample despite there may be biased in some ways. In Gursoy and Swanger [24], the response rate as low as 14 to $15 \%$ was considered indicative of the entire group and was acceptable. Therefore, $47 \%$ of engineering students responded in this study was acceptable since the students were also drawn from a random sample and we have identified no bias on any group of engineering students (e.g. gender, nationality, etc.).

Table 1. Demographic Data

\begin{tabular}{cc|c|c|c|c}
\hline \multirow{2}{*}{ Gender } & \multicolumn{3}{|c|}{ Course } & Total \\
\cline { 3 - 5 } & Male & Engineering & Social Science & Science & \\
\cline { 2 - 5 } & Female & 46 & 24 & 23 & 93 \\
\hline & Total & 56 & 39 & 67 & 116 \\
\hline
\end{tabular}

The respondents were studying on one of three foundation years: engineering, science and social science (business/arts). The expected mathematical learning outcomes of the students graduating from these courses were different. Among the engineering students, $82 \%$ were male and $18 \%$ were female. This is approximately the same gender split on the undergraduate programmes at the same institution (79/21). The gender bias of the respondents from the other two courses is opposite that of engineering namely there were more female respondents than male. On the business/arts course, $38 \%$ were males and $62 \%$ were females whilst for science students the gender split was $74 \% 26 \%$. The unequal gender split across the courses could also introduce some bias into the result and conclusions since the majority of the males (49\%) are engineering students and majority of the females $(58 \%)$ are science students.

\subsection{Gaming Experience}

To explore students' attitude to learning mathematics with digital games, there is a need to draw upon feedback and experience of students in playing digital games. According to the literature, students' attitude towards the use of computer technologies in learning mathematics is influenced by their attitude towards the subjects and the technology [6], [9]. Thus, it was significant to explore students' attitude towards digital games in general (i.e. technology), before exploring the students' attitude towards mathematics learning with digital games. It was hypothesized that students who love to play digital games would evidence better perceptions of mathematics learning with digital games.

Judging from the data collected, only $78 \%$ of the students reported playing digital games and $22 \%$ of them reported they did not play any types of digital games. More males $(83 \%)$ than females (74\%) played digital games, but for those who did play, there was no significant gender difference in hours spent in playing digital games. Among all the students who played games, they spent an average of 1.76 hours per day playing digital games, males spent an average of 1.93 hours and females spent an average of 1.64 hours playing digital games. Majority of males $(60 \%)$ and females $(82 \%)$ spent about 1 to 2 hours per day playing digital games, but males (27\% played daily) significantly played game more frequently than females (19\% played daily). Moreover, $24 \%$ of the females had not played games for more than a month compared to males only $2.5 \%$. Majority of the students (57\%) played digital games on weekly basis and $64 \%$ of them had more than five years of gaming experience. In fact, majority of them $(72 \%)$ claimed moderate to expert level of gaming expertise. Generally, students enjoyed playing Facebook and digital games such as computer games or video games as shown in Table 2 and Table 3. 
Table 2. Students' Favourite Games on Facebook

\begin{tabular}{|c|c|c|c|c|c|c|}
\hline \multicolumn{2}{|r|}{ Science } & \multirow{2}{*}{$\begin{array}{l}\text { Social } \\
\text { Science } \\
\text { Candy } \\
\text { Crush }\end{array}$} & Engineering & \multirow{2}{*}{$\begin{array}{l}\text { Male } \\
\text { Tetris }\end{array}$} & \multirow{2}{*}{$\begin{array}{l}\text { Female } \\
\text { Candy } \\
\text { Crush }\end{array}$} & \multirow{2}{*}{$\begin{array}{l}\text { Overall } \\
\text { Candy } \\
\text { Crush }\end{array}$} \\
\hline $1^{\text {st }}$ & Candy Crush & & Tetris & & & \\
\hline $2^{\text {nd }}$ & Farmville & Tetris & Candy Crush & Candy Crush & Farmville & Tetris \\
\hline $3^{\text {rd }}$ & Diamond Dash & Farmville & $\begin{array}{l}\text { Texas HoldEm } \\
\text { Poker }\end{array}$ & 8 Ball Pool & $\begin{array}{l}\text { Diamond } \\
\text { Dash }\end{array}$ & Farmville \\
\hline $4^{\text {th }}$ & FarmVille 2 & Bejeweled & 8 Ball Pool & $\begin{array}{l}\text { Texas HoldEm } \\
\text { Poker }\end{array}$ & $\begin{array}{l}\text { Tetris } \\
\text { Bejeweled }\end{array}$ & $\begin{array}{l}\text { Diamond } \\
\text { Dash }\end{array}$ \\
\hline $5^{\text {th }}$ & Tetris & $\begin{array}{l}\text { Diamond } \\
\text { Dash }\end{array}$ & Bejeweled & $\begin{array}{l}\text { Farmville, } \\
\text { Bejeweled }\end{array}$ & Farmville 2 & Farmville 2 \\
\hline
\end{tabular}

On Facebook, the most popular games played by the students were Candy Crush, followed by Tetris, Farmville, Diamond Dash and Farmville 2. Candy Crush was also the most popular Facebook game among science, social science and female students. However, for engineering and male students, the most popular Facebook game was Tetris. In general, students loved to play puzzle (i.e. Candy Crush, Tetris, Diamond Dash) and simulation (Farmville, Farmville 2) games on Facebook.

Table 3. Students' Favourite Digital Game

\begin{tabular}{|c|c|c|c|c|c|c|}
\hline & Science & $\begin{array}{l}\text { Social } \\
\text { Science }\end{array}$ & Engineering & Male & Female & Overall \\
\hline $1^{\text {st }}$ & $\begin{array}{l}\text { Candy } \\
\text { Crush }\end{array}$ & FIFA & FIFA & FIFA & $\begin{array}{l}\text { Candy } \\
\text { Crush }\end{array}$ & $\begin{array}{l}\text { Candy } \\
\text { Crush }\end{array}$ \\
\hline $2^{\text {nd }}$ & The Sims & Call of Duty & \multirow{3}{*}{$\begin{array}{l}\text { Grand Theft } \\
\text { Auto } \\
\text { DotA } \\
\text { Call of Duty }\end{array}$} & DotA & The Sims & FIFA \\
\hline $3^{\text {rd }}$ & \multirow{3}{*}{$\begin{array}{l}\text { Tetris } \\
\text { Minion } \\
\text { Rush } \\
\text { Temple Run } \\
\text { Need for } \\
\text { Speed }\end{array}$} & $\begin{array}{l}\text { Candy } \\
\text { Crush } \\
\text { The Sims }\end{array}$ & & Call of Duty & Tetris & $\begin{array}{l}\text { Call of } \\
\text { Duty }\end{array}$ \\
\hline $4^{\text {th }}$ & & $\begin{array}{l}\text { Counter } \\
\text { Strike }\end{array}$ & & $\begin{array}{l}\text { Grand } \text { Theft } \\
\text { Auto }\end{array}$ & Temple Run & \multirow{2}{*}{$\begin{array}{l}\text { The Sims } \\
\text { DotA }\end{array}$} \\
\hline $5^{\text {th }}$ & & $\begin{array}{l}\text { Strike, } \\
\text { Subway surf }\end{array}$ & Minion Rush & Minion Rush & $\begin{array}{l}\text { Final } \\
\text { Fantasy }\end{array}$ & \\
\hline
\end{tabular}

Among all types of digital games (i.e. Facebook games, computer games or video games), the most popular game was also Candy Crush followed by FIFA, Call of Duty, The Sims and DotA. Candy Crush was the most popular puzzle game played by science and female students, whereas FIFA was the most popular sport game played by engineering, social science and male students. Based on students' favourite digital games, males preferred to play digital games in a few genres namely sports (i.e. FIFA), strategy role play (i.e. DotA), shooter (i.e. Call of Duty) and action adventure (i.e. Grand Auto Theft, Minion Rush) games. As for females, they generally preferred to play puzzle (i.e. Candy Crush, Tetris), simulation (i.e. The Sims), action adventure (i.e. Temple Run) and role play (i.e. Final Fantasy) games.

Table 4. Agreement to Love for Games Genres in Percentage (\%)

\begin{tabular}{|c|c|c|c|c|c|c|c|c|c|}
\hline & Simulation & Racing & Sports & $\begin{array}{l}\text { Role } \\
\text { Play }\end{array}$ & $\begin{array}{c}\text { Action } \\
\text { Adventure }\end{array}$ & Strategy & Fighting & Puzzle & Shooter \\
\hline Science & 26.4 & 30.6 & 18.1 & 20.8 & 40.3 & 22.2 & 33.3 & 29.2 & 34.7 \\
\hline $\begin{array}{l}\text { Social } \\
\text { Science }\end{array}$ & 66.7 & 75.0 & 20.8 & 54.2 & 75.0 & 45.8 & 60.4 & 66.7 & 75.0 \\
\hline Engineering & 56.1 & 46.3 & 46.3 & 75.6 & 87.8 & 78.0 & 46.3 & 39.0 & 73.2 \\
\hline Male & 41.6 & 63.6 & 46.8 & 61.0 & 81.8 & 61.0 & 45.5 & 24.7 & 83.1 \\
\hline Female & 50.0 & 38.1 & 7.1 & 29.8 & 45.2 & 27.4 & 44.0 & 59.5 & 32.1 \\
\hline Overall & 46.0 & 50.3 & 26.1 & 44.7 & 62.7 & 43.5 & 44.7 & 42.9 & 56.5 \\
\hline
\end{tabular}

Table 4 shows the percentage of students who either agreed or strongly agreed that they love a certain game genre. For example, in the questionnaire, students were asked "I love to play 
simulation games" with multiple options of - strongly disagree, disagree, not sure, agree, strongly agree. Further analysis of games genres in Table 4 discovered that more than $50 \%$ of males agreed or strongly agreed that they loved to play racing, role play, action adventure, strategy and shooter games. For females, more than $50 \%$ of them agreed or strongly agreed that they loved to play puzzle and simulation games. The non-parametric Mann-Whitney $U$ test showed that males significantly $(p<0.05)$ loved to play sports, role play, action adventure, strategy and shooter more than females. Conversely, females significantly $(p<0.05)$ loved to play puzzle games more than males. However, there were no significant gender differences $(p>0.05)$ in preferences for simulation, racing and fighting games. A breakdown by course showed that there were no significant $(p>0.05)$ differences in preference for games genres between engineering, science and social science students except for puzzle games. Science and social science students significantly $(p<0.05)$ loved to play puzzle games more than engineering students. Overall, the most favourable games genres were action adventure, shooter and racing games. Surprisingly, Candy Crush (i.e. puzzle game) and FIFA (i.e. sports) which were ranked as top two most popular digital games played among the students in Table 3 were rated as the least popular games genres in Table 4, in which puzzle $(42.9 \%)$ and sports $(26.1 \%)$ games. One explanation could be that the students were not clear with the game genres in spite of the examples were given in the questionnaires. Furthermore, there is a grey area in games classifications because some games could be classified in more than one genre (e.g. DotA is a strategy and role play game). Therefore, a fuller review of digital games played by the students in Table 3 could give a better picture of what games genres favoured by the students.

Gaming data in this section has showed that $78 \%$ of the students played digital games. On average, most of the students were active gamers (i.e. played 1.76 hours per day). Active gamers play digital games for more than 7 hours per week [25]. The students were quite positive towards digital games as they also played a variety of Facebook, video or computer games. For instance, males loved to play racing, role play, action adventure, strategy and shooter games; while females loved to play puzzle and simulation games. Based on this finding, it was conjectured that students might be positive towards mathematics learning with digital games.

\subsection{Attitude to Learning Mathematics with Digital Games}

Before calculating the score for each subscale in MTAS, Cronbach's alpha was calculated to confirm the internal consistency and hence reliability of the scale. The values for each subscale (MC, 0.901; TC, 0.806; BE, 0.814; AE, 0.797 and MTg, 0.877) indicating a strong or acceptable degree of internal consistency. Each subscale score (minimum 4 - maximum 20) was obtained by adding the responses of four items and result is shown in Table 5.

Table 5. Distribution of MTAS Subscale Scores for 209 Students

\begin{tabular}{l|c|c|c|c|c}
\hline & MC & AE & BE & TC & MTg \\
\hline Mean & 14.3 & 15.7 & 14.8 & 13.9 & 13.0 \\
\hline Median & 15.0 & 16.0 & 15.0 & 14.0 & 13.0 \\
\hline Std. Deviation & 3.1 & 3.0 & 3.3 & 2.7 & 3.3 \\
\hline
\end{tabular}

Score: 4 - 12 low, neutral or negative attitude, 13 -16: moderately high, $17-20$ : a very positive attitude

The MTAS subscale scores are provided in Table 5 and these result showed that the students' attitude was moderately high in all the five subscales (mathematics confidence MC, affective engagement $\mathrm{AE}$, behavioural engagement $\mathrm{BE}$, confidence with technology $\mathrm{TC}$, attitude to learning mathematics with digital game MTg). In general, the students were more positive toward mathematics learning (i.e. MC, $\mathrm{AE}$ and $\mathrm{BE}$ ) in compared to the use of technology (i.e. TC and MTg). The students were only slightly positive towards the use of digital games in learning mathematics [i.e. MTg =13]. In the next two sections we report on the responses of all students on the MTAS variables in respect to their gender and course.

\subsubsection{Gender Differences}

Mann-Whitney U Test (i.e. results in Table 6, Table 7 and Table 8) was used to determine if there were gender differences in MTAS subscale scores. 
Table 6. Median of MTAS Subscale Scores according to Gender

\begin{tabular}{c|c|c}
\hline \multirow{2}{*}{} & \multicolumn{2}{|c}{ Gender } \\
\cline { 2 - 3 } & Male & Female \\
\hline $\mathrm{MC}$ & 15.0 & 14.0 \\
\hline $\mathrm{BE}$ & 15.0 & 16.0 \\
\hline $\mathrm{TC}$ & 14.0 & 16.0 \\
\hline $\mathrm{MTg}$ & 14.0 & 14.0 \\
\hline
\end{tabular}

[Score: 4 - 12 low, neutral or negative attitude, 13 -16: moderately high, 17 - 20: a very positive attitude]

Table 7. Gender Differences in Affective Domain (Ranks)

\begin{tabular}{c|c|c|c|c}
\hline & Gender & $\mathrm{N}$ & Mean Rank & Sum of Ranks \\
\hline \multirow{3}{*}{ MC } & male & 93 & 115.34 & 10727.00 \\
\cline { 2 - 5 } & female & 116 & 96.71 & 11218.00 \\
\cline { 2 - 5 } AE & Total & 209 & & 9310.00 \\
\cline { 2 - 5 } & male & 93 & 100.11 & 12635.00 \\
\cline { 2 - 5 } & female & 116 & 108.92 & 8708.50 \\
\hline \multirow{3}{*}{ BE } & Total & 209 & & 13236.50 \\
\cline { 2 - 5 } & male & 93 & 93.64 & 10502.00 \\
\cline { 2 - 5 } TC & female & 116 & 114.11 & 11443.00 \\
\cline { 2 - 5 } & Total & 209 & 112.92 & 9133.50 \\
\cline { 2 - 5 } & female & 93 & 98.65 & 12811.50 \\
\hline \multirow{3}{*}{ MTg } & Total & 209 & & \\
\cline { 2 - 5 } & male & 93 & 98.21 & \\
\cline { 2 - 5 } & female & 116 & 110.44 & \\
\hline
\end{tabular}

Table 8. Gender Differences in Affective Domain using Mann-Whitney U Test

\begin{tabular}{l|c|c|c|c|c}
\hline & MC & AE & BE & TC & MTg \\
\hline Mann-Whitney U & 4432.000 & 4939.000 & 4337.500 & 4657.000 & 4762.500 \\
\hline Wilcoxon W & 11218.000 & 9310.000 & 8708.500 & 11443.000 & 9133.500 \\
\hline Z & -2.229 & -1.055 & -2.446 & -1.711 & -1.463 \\
\hline Asymp. Sig. (2-tailed) & .026 & .291 & .014 & .087 & .143 \\
\hline
\end{tabular}

A Mann-Whitney $U$ test indicated that males $(\mathrm{Mdn}=15)$ had greater confidence in mathematics [MC] than females $(\mathrm{Mdn}=14), \mathrm{U}=4432, p<0.05, r=0.15$. However, the effect size $(r=0.15)$ showed that there was only a trivial difference between the males and females in their confidence in mathematics. This result indicated that males had greater confidence in mathematics than females and this finding had a $95 \%$ chance of being true despite the difference being trivial. In other words, we were $95 \%$ confirmed that males were slightly more confident in mathematics than females. It should be noted that statistical significance $(p)$ only showed whether there was a difference between males and females in mathematics confidence (i.e. probability or how likely a result was due to chance), but the $p$ value would not reveal the size of the difference. In fact, the magnitude of the difference was measured by the effect size $(r)$. According to Cohen and Glass as cited in [26], both statistical significance $(p)$ and effect size $(r)$ were essential results to be reported in any research investigation. Unfortunately, many research studies do not report the effect size, while obviously showing the $p$ value that was not sufficient for reader to fully comprehend the result [26]. Hence, this study would prominently report both the statistical significance $(p)$ and effect size $(r)$ values in data analysis.

A Mann-Whitney $U$ test also indicted that females $(\mathrm{Mdn}=16)$ behaved more positively in learning mathematics $[\mathrm{BE}]$ than males $(\mathrm{Mdn}=14), \mathrm{U}=4337.5, p<0.05, r=0.17$. Further analysis on the effect size $(r=0.17)$ showed that there was a trivial difference in the behaviour of learning mathematics between males and females. This result indicated that females behaved more positively than males in learning mathematics and this finding had a $95 \%$ chance of being true despite the difference was trivial. In other words, we were $95 \%$ confirmed that females behaved slightly more positively than males in learning mathematics. Lastly, Mann-Whitney U tests indicated that males and females were not significantly different in how they feel about mathematics [AE], $\mathrm{U}=4939, p>0.05, r=0.07$; their technology confidence [TC], $\mathrm{U}=4657, p>$ 
$0.05, r=0.12$ and their attitude to learning mathematics with digital game [MTg], $\mathrm{U}=4762.50, p>$ $0.05, r=0.10$. To conclude, our analysis using Mann-Whitney U test indicated that the distribution of AE, TC and MTg were not significantly different between males and females. Approximately $50 \%$ of males in this study were engineering students with a higher mathematics entry requirement (i.e. minimum $\mathrm{B}+$ in additional mathematics and mathematics) and $91 \%$ of females in this study were science or social science students with lower mathematics entry requirement (i.e. minimum B in mathematics for science/business and minimum $\mathrm{C}$ for arts and education). Since the majority of females may have a lower grade in mathematics, they may have less confidence in mathematics (i.e. lower MC), and study harder (i.e. higher BE) to obtain a better mathematics result. Obviously, the slight differences of $\mathrm{MC}$ and $\mathrm{BE}$ between males and females might be affected by the unequal gender splits across the courses with different mathematics entry requirement.

\subsubsection{Course Differences}

A Kruskal-Wallis H Test was used to determine if there were course differences in MTAS subscale scores and results were shown in Table 9, Table 10 and Table 11.

Table 9. Median of MTAS Subscale Scores according to Course

\begin{tabular}{l|c|c|c}
\hline \multirow{2}{*}{} & \multicolumn{3}{|c}{ Course } \\
\cline { 2 - 4 } & Engineering & Science & Social Science \\
\hline $\mathrm{MC}$ & 16.0 & 15.0 & 14.0 \\
\hline $\mathrm{AE}$ & 16.0 & 16.0 & 15.0 \\
\hline $\mathrm{BE}$ & 15.5 & 16.0 & 14.0 \\
\hline $\mathrm{TC}$ & 14.0 & 14.0 & 14.0 \\
\hline $\mathrm{MTg}$ & 12.0 & 14.0 & 12.0 \\
\hline
\end{tabular}

[Score: 4 - 12 low, neutral or negative attitude, 13 -16: moderately high, 17-20: a very positive attitude]

Table 10.Course Differences in Affective Domain (Ranks)

\begin{tabular}{c|c|c|c}
\hline & Course & N & Mean Rank \\
\hline \multirow{4}{*}{ MC } & Science & 90 & 102.94 \\
\cline { 2 - 4 } & Social Science & 63 & 82.45 \\
\cline { 2 - 4 } & Engineering & 56 & 133.67 \\
\hline \multirow{4}{*}{ AE } & Total & 209 & \\
\cline { 2 - 4 } & Science & 90 & 111.19 \\
\cline { 2 - 4 } & Social Science & 63 & 85.79 \\
\cline { 2 - 4 } & Engineering & 56 & 116.66 \\
\hline \multirow{4}{*}{ BE } & Total & 209 & \\
\cline { 2 - 4 } & Science & 90 & 114.47 \\
\cline { 2 - 4 } & Social Science & 63 & 89.60 \\
\hline \multirow{5}{*}{ TC } & Engineering & 56 & 107.11 \\
\cline { 2 - 4 } & Total & 209 & 102.22 \\
\cline { 2 - 4 } & Science & 90 & 105.47 \\
\cline { 2 - 4 } MTg & Eocial Science & 63 & 108.95 \\
\cline { 2 - 4 } & Engineering & 56 & \\
\cline { 2 - 4 } & Total & 209 & 115.76 \\
\cline { 2 - 4 } & Science & 90 & 96.06 \\
\hline
\end{tabular}

Table 11.Course Differences in Domain using Kruskal Wallis Test

\begin{tabular}{c|c|c|c|c|c}
\hline & $\mathrm{MC}$ & $\mathrm{AE}$ & $\mathrm{BE}$ & $\mathrm{TC}$ & $\mathrm{MTg}$ \\
\hline Chi-Square & 21.742 & 9.530 & 6.431 & .440 & 5.098 \\
\hline $\mathrm{df}$ & 2 & 2 & 2 & 2 & 2 \\
\hline Asymp. Sig. & .000 & .009 & .040 & .802 & .078 \\
\hline
\end{tabular}

A Kruskal-Wallis $\mathrm{H}$ test showed that there was a statistically significant difference in mathematics confidence $[\mathrm{MC}]$ between students studying in different courses, $\chi 2(2)=21.74, p<0.01$, with the highest mean rank for mathematics confidence score of 133.67 for engineering students, followed by 102.94 for science students and 82.45 for social science students. To determine which groups of students were significantly different in mathematics confidence [MC], the Mann-Whitney U test was conducted on each pair of the courses. Results revealed that engineering students $(\mathrm{Mdn}=16)$ 
had slightly greater confidence in mathematics $[\mathrm{MC}]$ than science students $(\mathrm{Mdn}=15), \mathrm{U}=$ 1743.50, $p<0.01, r=0.26$. Similarly, science students $(\mathrm{Mdn}=15)$ also had slightly greater confidence in mathematics [MC] than social science students $(\mathrm{Mdn}=14), \mathrm{U}=2243.50, p<0.05$, $r=0.18$. However, engineering students $(\mathrm{Mdn}=16)$ had moderately greater confidence in mathematics than social science students $(\mathrm{Mdn}=14), \mathrm{U}=935.00, \mathrm{p}<0.01, \mathrm{r}=0.41$.

A Kruskal-Wallis $\mathrm{H}$ test also showed that there was a statistically significant difference in how students feel about mathematics [AE] between students studying in different courses, $\chi 2(2)=9.53$, $\mathrm{p}<0.01$, with the highest mean rank for affective engagement score of 116.66 for engineering students, followed by 111.19 for science students and 85.79 for social science students. Follow up with Mann-Whitney $U$ test revealed that there was no significant difference between engineering and science students in $\mathrm{AE}$, however both engineering $(\mathrm{Mdn}=16)$ and science students $(\mathrm{Mdn}=16)$ were feeling slightly more positive towards mathematics [AE] than social science students $(\mathrm{Mdn}=15), \mathrm{U}=1251, p<0.01, r=0.25 ; \mathrm{U}=2137.5, p<0.01, r=0.21$.

For [BE], a Kruskal-Wallis $\mathrm{H}$ test also showed that there was a statistically significant difference in how students behave in learning mathematics between students studying in different courses, $\chi$ $2(2)=6.43, p<0.05$, with the highest mean rank for behavioural engagement score of 114.47 for science students, followed by 107.11 for engineering students and 89.6 for social science students. A follow up with Mann-Whitney $U$ test revealed there was no significant difference between science and engineering students, however science $(\mathrm{Mdn}=16)$ and engineering students $(\mathrm{Mdn}=15.5)$ were behaving slightly more positive towards mathematics $[\mathrm{BE}]$ than social science students $(\mathrm{Mdn}=14), \mathrm{U}=2149, p<0.01, r=0.21 ; \mathrm{U}=1251, p<0.01, r=0.25$.

Lastly, a Kruskal-Wallis $\mathrm{H}$ test showed no statistically significant differences in technology confidence [TC] and attitude towards mathematics learning with digital game [MTg] among students studying in different courses.

\subsubsection{Relationship of MTg according to Gender and Course}

Table 12 presents the correlations between the MTAS subscale scores for the students in respect of gender and course of study. None of the variables (MC, AE, BE, TC and MTg) were normally distributed, thus non-parametric Spearman's correlation coefficient $\left(r_{s}\right)$ was used to measure the strength of the linear relationship between two variables. A Spearman's correlation was used to determine the relationship between all the MTAS subscale scores, and also for males and females; engineering, social science and science students. There were statistically significant $(p<0.01)$ positive correlations (weak or moderate) between all pairs of combined $\mathrm{MC}, \mathrm{AE}, \mathrm{BE}, \mathrm{TC}$ and MTg. Students' confidence in mathematics [MC], behavioural engagement [BE] and affective engagement $[\mathrm{AE}]$ were moderately positive correlated with each other. This result indicated that students with greater confidence in mathematics normally behaved and felt more positive towards mathematics learning, and vice versa.

The focus of this study was to determine students' attitude towards mathematics learning with digital game [MTg]. Students' attitude towards mathematics learning with digital game [MTg] had the strongest moderate, positive correlation with $\mathrm{AE}, r_{\mathrm{s}}=0.337, p<0.01$ and also weakly positive correlated with MC, BE and TC. Thus, students' confidence in technology [TC] and attitude towards mathematics [MC, $\mathrm{AE}, \mathrm{BE}]$ had little positive impact on students' attitude towards mathematics learning with digital games [MTg].

Table 12. Correlations according to Gender and Course

\begin{tabular}{|c|c|c|c|c|c|c|}
\hline & & $\mathrm{MC}$ & $\mathrm{AE}$ & $\mathrm{BE}$ & $\mathrm{TC}$ & MTg \\
\hline \multirow{6}{*}{$\mathrm{MC}$} & Combined & & $.585^{* *}$ & $.479^{* *}$ & $.272^{* *}$ & $.190^{* *}$ \\
\hline & Male & & $608^{* *}$ & $.533^{* *}$ & $232^{*}$ & $209^{*}$ \\
\hline & Female & & $.620^{* *}$ & $.512^{* *}$ & $.335^{* *}$ & $208^{*}$ \\
\hline & Engineering & & $683^{* *}$ & $.471^{* *}$ & $270^{*}$ & .210 \\
\hline & Social Science & & $.448^{* *}$ & $.492^{* *}$ & $402^{* *}$ & $339^{* *}$ \\
\hline & Science & & $.568^{* *}$ & $.500^{* *}$ & .205 & .116 \\
\hline \multirow{6}{*}{$\mathrm{AE}$} & Combined & & \multirow{6}{*}{1} & $.493^{* *}$ & $205^{* *}$ & $337^{* *}$ \\
\hline & Male & & & $.471^{* *}$ & $261^{*}$ & $403^{* *}$ \\
\hline & Female & & & $.481^{* *}$ & 177 & $258^{* *}$ \\
\hline & Engineering & & & $.489^{* *}$ & $370^{* *}$ & $.341^{*}$ \\
\hline & Social Science & & & $.385^{* *}$ & .222 & $482^{* *}$ \\
\hline & Science & & & $.508^{* *}$ & .078 & $.233^{*}$ \\
\hline \multirow{2}{*}{$\mathrm{BE}$} & Combined & & & \multirow{2}{*}{1} & $240^{* *}$ & $.208^{* *}$ \\
\hline & Male & & & & $236^{*}$ & .118 \\
\hline
\end{tabular}




\begin{tabular}{|c|c|c|c|}
\hline & Female & $.306^{* *}$ & $271^{* *}$ \\
\hline & Engineering & 247 & .126 \\
\hline & Social Science & $325^{* *}$ & $321^{*}$ \\
\hline & Science & .201 & .127 \\
\hline \multirow{6}{*}{$\mathrm{TC}$} & Combined & \multirow{6}{*}{801} & $211^{* *}$ \\
\hline & Male & & $281^{* *}$ \\
\hline & Female & & .167 \\
\hline & Engineering & & .203 \\
\hline & Social Science & & $258^{*}$ \\
\hline & Science & & .206 \\
\hline
\end{tabular}

**. Correlation is significant at the 0.01 level (2-tailed).

*. Correlation is significant at the 0.05 level (2-tailed).

The breakdown of correlation by gender revealed that males and females tended to react differently to use of digital game in learning mathematics $[\mathrm{MTg}]$. For males, MTg had the strongest moderate, positive correlation with $\mathrm{AE}, r_{\mathrm{s}}=0.403, p<0.01$, followed by weak positive correlations with TC, $r_{\mathrm{s}}=0.281, p<0.01$ and MC, $r_{\mathrm{s}}=0.209, p<0.05$. This indicated that male students who feel more positive towards mathematics were more likely to prefer the use of digital games to learn mathematics. Nevertheless, other factors such as their confidence in mathematics and technology did have a little influence on their attitude towards mathematics learning with digital game. Therefore, educators could enhance male students' interest in learning mathematics if digital games were to be adopted for teaching and learning. As for females, MTg were weakly positive correlated with $\mathrm{BE}, r_{\mathrm{s}}=0.271, p<0.01$, followed by $\mathrm{AE}, r_{s}=0.258, p<0.05$ and $\mathrm{MC}, r_{\mathrm{s}}=0.208$, $p<0.05$. This result showed that female students' attitude (confidence, behaviour and affective) in learning mathematics had little, but positive impact on their attitude towards mathematics learning with digital game.

Further breakdown of correlation by course of study revealed that engineering, social science and science students reacted differently to the use of digital game in learning mathematics [MTg]. For engineering and science students, MTg were only significantly positive correlated with AE, $r_{s}=0.341$ (engineering), $r_{s}=0.233$ (science), $p<0.05$. This result indicated that engineering and science students who felt more positive towards mathematics were slightly more likely to use digital game for learning mathematics. Other factors such as their mathematics confidence, behaviour in learning mathematics and technology confidence had no impact on their attitude towards use of digital game for learning mathematics. As for social science students, MTg was correlated with all other variables. MTg was moderately positive correlated with $\mathrm{AE}\left(r_{s}=0.482\right.$, $p<0.01), \mathrm{MC}\left(r_{s}=0.339, p<0.01\right), \mathrm{BE}\left(r_{s}=0.321, p<0.05\right)$ and weakly positive correlated with TC $\left(r_{s}=0.258, p<0.05\right)$. This result showed that social science students' attitude towards mathematics learning with digital games was influenced by their attitude towards mathematics and their technology confidence.

Based on this analysis, students' interest in mathematics [AE] had the greatest impact on students' attitude towards mathematics learning with digital game. Students from all categories of field of study and gender groups were more likely to use digital game to learn mathematics if they have strong interest in mathematics.

\section{Discussion}

In the previous data analysis section, statistical significance and effect size were reported in all statistical analysis, but most of the significant findings were found to have a small effect size. In fact, interpretation of effect size is very subjective and debatable. For instance, a small effect size on an important variable (e.g. health) or a small effect size that accumulates over a period of time is important [27]. However, a large effect size on a trivial variable (e.g. rating on a scale) or a large effect size that does not persist may not be important [27]. Since MTAS variables are measured using a rating on a scale, the large effect size may not be important according to Mitchell and Jolley [27]. Nevertheless in Pierce et al. [6], a small effect size of MTAS variables was reported to be important. Thus, this study would not ignore the small effect sizes reported in the data analysis.

Gaming data collected in this study showed that most of the students liked to play different types of digital games and they were considered as active gamers. Males were reported to play digital games more frequently than females and this result was consistent with the findings of Phan et al. 
[28] that males tended to play video games at all times than females. Students in this study were reported to spend 1.76 hours per day playing digital games, which was lower than 3.26 hours reported in Phan et al. [28], but slightly higher than 1.57 hours reported in Cole and Griffiths [29]. Coincide with Cole and Griffiths [29], males (1.93 hours per day) and females (1.64 hours per day) in this study had no significant difference in time spent on playing digital games. Thus, this finding contradicted with many earlier studies reported that males spent more time playing digital games than females [28], [30], [31]. Males loved to play digital games from the sport (e.g. FIFA), strategy role play (e.g. DotA), action adventure (Grand Auto Theft) and shooter (e.g. Call of Duty) genres more than females. This result agreed with some earlier studies that males preferred sport [30], role play [28], [30], action adventure [28], strategy [28], [30] and shooter [30] games. As for females, they loved to play puzzle games (e.g. Candy Crush, Tetris) more than males. This result supports previous studies [28], [30] that females love to play puzzle games. However, males and females in this study had no significant difference in preference for simulation, racing and fighting game, and this results contradicted with Phan et al. [28], whereby females prefer simulation game and males prefer fighting and racing games. Although students' preference for games was varied across different demographic groups, most of the students liked to play games. Students' attitude towards a technology do influence their attitude towards the use of the technology in learning mathematics [6], [9]. Since most of the students regardless of gender or course liked to play digital games, it was conjectured that they would be positive towards the idea of learning with digital games.

Surprisingly, the MTAS score indicated that the students were not very positive towards the use of digital games in learning mathematics. Students' attitude towards mathematics learning with digital games was greatly influenced by how they felt about mathematics, and little influenced by their mathematics confidence, technology confidence and behaviour in learning mathematics. This implied that if students claimed to love mathematics, they are more likely to use digital games to learn mathematics. However, if students claim to dislike mathematics, the introduction of digital games to learn mathematics may not be feasible. A further breakdown according to gender revealed that males' attitude towards learning mathematics with digital games was mainly influenced by their positive feelings towards mathematics, technology confidence and mathematics confidence. Our findings agree with Pierce et al. [6] and Vale and Leder [32], whereby males who had more confidence in technology were more likely to be positive about the use of computers in mathematics. As for females, they were more likely to have positive attitude towards mathematics learning with digital games if they had more positive attitude (feeling, behaviour and confidence) towards mathematics. This finding contradicts with Pierce et al. [6] who found females with more confidence in mathematics tended to have more negative attitude towards mathematics learning with technology. In this study, females' confidence in technology was found to have no impact on their attitude towards mathematics learning with digital games and this contradicted with Vale and Leder [32] who found females who rated themselves highly in achievement in computing were more likely to have a positive attitude to computer-based mathematics. Students from all the three courses were more likely to have positive attitude towards mathematics learning with digital games if they had interest in learning mathematics, but for social science students, other factors such as mathematics confidence, behaviour in learning mathematics and technology confidence do play a little impact too.

Analysis of gender differences also showed that males' confidence in mathematics was significantly higher than females. This result is aligned with Pierce et al. [6] who also found that males were generally more confident in mathematics. However, this could be that females tend to report less confidence and less self-belief in their ability though they perform as well as males [1], [5]. Conversely, females in this study significantly behaved more positively in learning mathematics than males. This result supported by Yaratan \& Kasapoğlu [12] but contradicted Pierce et al. [6] who reported no significant difference between males and females in behavioural engagement. However we may need to conjecture a possible Malaysian factor here. In other aspects such as how students feel about mathematics, confidence with technology and attitude towards mathematics learning with digital games, there were no significant differences between males and females. These results were contrasting to those of Pierce et al. [6] who found males were significantly more positive than females in all these three aspects. Vale [9] also found that males were more positive than females for use of technology in learning mathematics. One explanation for this is the different geographical location of the study; both studies i.e. [6], [32] were conducted in Australia/Australasia where males outperform females in mathematics, but this phenomenon was contrasting in Malaysia, whereby females outperform males in mathematics [1]. It may be that high performing students have better attitude towards mathematics and learning 
mathematics using technology. Furthermore, both earlier studies were conducted in 2004 [32] and 2007 [6], before the advent of smartphones. The use of technology has significantly increased and changed since the arrival of smartphones that enable people to play games at their convenience time. Though Yong and Gates [33] reported that females were characterized to be more digitally native than males, this study did not show any significant difference between males and females in confidence with technology. Nevertheless, this study coincided with Vekiri [34] who mentioned that there was no support that males were more positive in information communications technology (ICT) self-efficacy and value beliefs than females.

Analysis of courses enrolled showed engineering students significantly had the highest confidence in mathematics, followed by science students and lastly social science students. Similarly, engineering and science students have more positive feelings and behave more positively in learning mathematics compared to social science students, though the difference was trivial. In general, engineering students had the highest confidence and interest in mathematics, but science students had the best learning behaviour in mathematics. This may be explained by the higher mathematics entry requirement onto the engineering foundation programme compared to science and social science. Students with good mathematics performance may have more confidence in the subject. Equally, self-confidence in mathematics is crucial as it is strongly correlated with achievement [35]. This further implied that males (82\%) which were the majority of engineering students had greater confidence in mathematics. As for science students, their interest and behaviour in learning mathematics were similar to engineering students, yet they were lack of confidence in mathematics. Females (74\%) who were the majority of science students reported a lack of confidence in mathematics and this supports the literature [1], [6] that females were less confidence and less self-belief in their ability in mathematics.

In interpreting all the gender and course differences, it is important to highlight that the main factor influencing students' attitude to the use of digital games in learning mathematics is how they felt about mathematics, whether they like or dislike mathematics. In this study, males and females had no significant difference in their attitude towards mathematics. However, social science students were significantly having a lower interest in mathematics compared to engineering and science students. Thus, engineering and science students were more likely to use digital game to learn mathematics compared to social science students. Educators may need to put more effort in helping social science students in developing their interest in mathematics.

\section{Conclusion}

In this study, it was found that most of the university foundation students liked to play different types of digital games. However, they were not very positive towards the use of digital games in learning mathematics, and their attitude was essentially influenced by their mathematics interest. Since the students had a moderate interest in mathematics, they were not too optimistic towards the use of digital games in learning mathematics. Looking from a different perspective, the students might be doubtful with the use of computer technology to learn in a formal classroom setting. This finding could imply that if students experienced a positive learning outcome when learning mathematics with digital games, they were more likely to build a strong interest in the subject learned. In a way, choosing the right game is important. If the mathematics games are designed specifically for male students, they could be originated from a few genres such as sport, racing, shooter, action adventure, role play and strategy. Male students who experience positive learning outcome with mathematics computer games may have more interest and confidence in mathematics. However, if the mathematics games are designed for female students, puzzle and simulation games could be used. Female students who experience positive learning outcome with mathematics computer games may behave more positively, and have more interest and confidence in mathematics. To a certain extent, the use of digital games in learning mathematics may also boost up the females' low confidence in mathematics as reported in this study. Conversely, if the mathematics games are designed for students from different courses, all games genres are appropriate with the exception of engineering students who may not like to play puzzle games. Engineering and science students who experience positive learning outcome with mathematics computer games may build a strong interest in mathematics. For social science students, the positive learning outcome may enhance their interest, confidence and learning behaviour in mathematics. This study could give some implications to educators for potential use of digital games to learn mathematics. The deployment of mathematics computer games is related to the students' attitude towards mathematics, and the type of digital games used. If students have no 
interest in the subject learned, the deployment of mathematics computer game is relatively impractical. This finding provides an insight that can be used by either teachers or researchers interested in trilling teaching innovations which include the use of digital game in teaching mathematics at tertiary education in other developing countries. This is a preliminary study that involved the students' survey, and a more comprehensive study should be conducted in the future to include the teachers' and parents' viewpoint as they play a major role in the children's education.

\section{References}

[1] PISA, "PISA 2012 results in focus - what 15-year-olds know and what they can do with what they know," 2012. [Online]. Available: http://www.oecd.org/pisa/keyfindings/pisa-2012results-overview.pdf.

[2] Chang S. H., "Learning mathematics through computer games," in Proceedings of the 14th Asian Technology Conference in Mathematics, 2009, pp. 168-177.

[3] Bragg L., "Children's perspectives on mathematics and game playing," in Proceedings of the 26th annual conference of the Mathematics Education Research Group of Australasia, 2003, pp. 160-167.

[4] K. Kislenko, "Structuring students' beliefs in mathematics: A Norwegian case," in In Current State of Research on Mathematical Beliefs XII. Proceedings of the MAVI-12 Workshop., 2006, pp. 45-57.

[5] McLeod D. B, "Research on affect in mathematics education: A reconceptualization," in Handbook of research on mathematics teaching and learning: A project of the National Council of Teachers of Mathematics, D. A. Grouws, Ed. New York: MacMillan, 1992, pp. 575-596.

[6] Pierce R., Stacey K., and Barkatsas A., “A scale for monitoring students' attitudes to learning mathematics with technology," Comput. Educ., vol. 48, no. 2, pp. 285-300, Feb. 2007. http://dx.doi.org/10.1016/j.compedu.2005.01.006

[7] Marchis I., "Factors that influence secondary school students' attitude to mathematics," Procedia - Soc. Behav. Sci., vol. 29, no. 1, pp. 786-793, Jan. 2011. http://dx.doi.org/10.1016/j.sbspro.2011.11.306

[8] Vandecandelaere M., Speybroeck S., Vanlaar G., De Fraine B., and Van Damme J., "Learning environment and students' mathematics attitude," Stud. Educ. Eval., vol. 38, no. 3, pp. 107120, Sep. 2012. http://dx.doi.org/10.1016/j.stueduc.2012.09.001

[9] Vale C., "Trends and factors concerning gender and mathematics in Australasia," in 11th International Congress on Mathematical Education, 2008.

[10] Barkatsas A., Kasimatis K., and Gialamas V., "Learning secondary mathematics with technology: Exploring the complex interrelationship between students' attitudes, engagement, gender and achievement," Comput. Educ., vol. 52, no. 3, pp. 562-570, Apr. 2009. http://dx.doi.org/10.1016/j.compedu.2008.11.001

[11] Pilli O. and Aksu M., "The effects of computer-assisted instruction on the achievement, attitudes and retention of fourth grade mathematics students in North Cyprus," Comput. Educ., vol. 62, pp. 62-71, Mar. 2013. http://dx.doi.org/10.1016/j.compedu.2012.10.010

[12] Yaratan H. and Kasapoğlu L., "Eighth Grade Students' Attitude, Anxiety, and Achievement Pertaining to Mathematics Lessons," Procedia - Soc. Behav. Sci., vol. 46, pp. 162-171, Jan. 2012. http://dx.doi.org/10.1016/j.sbspro.2012.05.087

[13] Van Eck R., "Digital Game-Based Learning: It's Not Just the Digital Natives Who Are Restless,” Educ. Rev., vol. 41, no. 2, pp. 16-30, Oct. 2006.

[14] Egenfeldt-Nielsen S., "Third generation educational use of computer games," J. Educ. Multimed. Hypermedia, vol. 16, no. 3, pp. 263-281, 2007.

[15] Kiili K., "Evaluations of and Experiential Gaming Model," An Interdiscip. J. Humans ICT Environ., vol. 2, no. 2, pp. 187-201, 2006.

[16] Ke F. and Grabowski B., "Gameplaying for maths learning: cooperative or not?," Br. J. Educ. Technol., vol. 38, no. 2, pp. 249-259, Mar. 2007. http://dx.doi.org/10.1111/j.14678535.2006.00593.x

[17] Holzinger A., Pichler A., Almer W., and Maurer H., "TRIANGLE: A Multi-Media test-bed for examining incidental learning, motivation and the Tamagotchi-Effect within a Game-Show like Computer Based Learning Module," Educ. Multimed. Hypermedia Telecommun., vol. 1, no. 1, pp. 766-771, 2001. 
[18] Rosas R., Nussbaum M., Cumsille P., Marianov V., Correa M., Flores P., Grau V., Lagos F., López X., López V., Rodriguez P., and Salinas M., "Beyond Nintendo: design and assessment of educational video games for first and second grade students," Comput. Educ., vol. 40, no. 1, pp. 71-94, Jan. 2003. http://dx.doi.org/10.1016/S0360-1315(02)00099-4

[19] Çankaya S. and Karamete A., "The effects of educational computer games on students' attitudes towards mathematics course and educational computer games," Procedia - Soc. Behav. Sci., vol. 1, no. 1, pp. 145-149, Jan. 2009. http://dx.doi.org/10.1016/j.sbspro.2009.01.027

[20] Johnson B. and Christensen L., Educational Research Quantitative, Qualitative and Mixed Approaches. Thousand Oaks, CA: Sage Publications, 2008.

[21] Mertens D. M., Research and Evaluation in Education and Psychology, 3rd ed. United States: Sage Publications, Inc., 2010.

[22] Fraenkel J. R. and Wallen N. E., How to Design and Evaluate Research in Education, 6th ed. Boston: Mc Graw Hill, 2006.

[23] Galbraith P. and Haines C., "Disentangling the nexus: Attitudes to mathematics and technology in a computer learning environment," Educ. Stud. Math., vol. 36, no. 3, pp. 275290, 1998. http://dx.doi.org/10.1023/A:1003198120666

[24]Gursoy D. and Swanger N., "Performance-enhancing internal strategic factors and competencies: Impacts on financial success,” Int. J. Hosp. Manag., vol. 26, no. 1, pp. 213-227, 2007. http://dx.doi.org/10.1016/j.ijhm.2006.01.004

[25] Simons M., de Vet E., Brug J., Seidell J., and Chinapaw M. J. M., "Active and non-active video gaming among Dutch adolescents: who plays and how much?," J. Sci. Med. Sport, vol. 17, no. 6, pp. 597-601, 2014. http://dx.doi.org/10.1016/j.jsams.2013.10.250

[26] Sullivan G. M. and Feinn R., "Using Effect Size-or Why the P Value Is Not Enough.," J. Grad. Med. Educ., vol. 4, no. 3, pp. 279-282, Sep. 2012. http://dx.doi.org/10.4300/JGME-D-1200156.1

[27] Mitchell M. L .and Jolley J. M., Research Design Explained, 7th ed. Cengage Learning, 2009.

[28] Phan M. H., Jardina J. R, Hoyle S., and Chaparro B. S., "Examining the Role of Gender in Video Game Usage, Preference, and Behavior," Proc. Hum. Factors Ergon. Soc. Annu. Meet., vol. 56, no. 1, pp. 1496-1500, Oct. 2012. http://dx.doi.org/10.1177/1071181312561297

[29] Cole H. and Griffiths M. D., "Social interactions in massively multiplayer online role-playing gamers.," Cyberpsychol. Behav., vol. 10, no. 4, pp. 575-83, Aug. 2007. http://dx.doi.org/10.1089/cpb.2007.9988

[30] Bonanno P. and Kommers P. A. M., "Gender differences and styles in the use of digital games,” Educ. Psychol. An Int. J. Exp. Educ. Psychol., vol. 25, no. 1, pp. 13-41, Feb. 2005. http://dx.doi.org/10.1080/0144341042000294877

[31] Sherry J. L, Lucas K., Greenberg B. S, and Lachlan K., "Video Game Uses and Gratifications as Predictors of Use and Game Preference," in Playing video games: Motives, responses, and consequences, vol. 24, P. Vorderer and J. Bryant, Eds. Mahwah, NJ: Lawrence Erlbaum, 2006, pp. 213-224.

[32] Vale C. M. and Leder G. C., "Student Views of Computer-Based Mathematics in the Middle Years: Does Gender Make a Difference?" Educ. Stud. Math., vol. 56, no. 3, pp. 287-312, 2004. http://dx.doi.org/10.1023/B:EDUC.0000040411.94890.56

[33] Yong S.-T. and Gates P., "Born Digital: Are They Really Digital Natives?," Int. J. eEducation, e-business, e-Management e-Learning, vol. 4, no. 2, pp. 102-105, 2014.

[34] Vekiri I., "Boys' and girls' ICT beliefs: Do teachers matter?," Comput. Educ., vol. 55, no. 1, pp. 16-23, 2010. http://dx.doi.org/10.1016/j.compedu.2009.11.013

[35] Thomson S. and Fleming N., Summing it up: Mathematics achievement in Australian schools in TIMSS 2002, vol. 2002. Camberwell: Australian Council for Educational Research, 2004. 


\section{Appendix}

\section{MATHEMATICS LEARNING \& USE OF DIGITAL GAME TO LEARN MATHEMATICS}

1. What is your perception towards MATHEMATICS learning? *

Mark only one oval per row.

\begin{tabular}{|c|c|c|c|c|c|}
\hline & $\begin{array}{l}\text { Hardly } \\
\text { Ever }\end{array}$ & Occasionally & $\begin{array}{c}\text { About Half the } \\
\text { time }\end{array}$ & Usually & $\begin{array}{l}\text { Nearly } \\
\text { Always }\end{array}$ \\
\hline I concentrate hard in mathematics. & O & O & $\mathrm{O}$ & O & O \\
\hline I try to answer questions the teacher asks. & $\mathrm{O}$ & $\mathrm{O}$ & $\mathrm{O}$ & O & O \\
\hline $\begin{array}{l}\text { If I make mistakes, I work until I have } \\
\text { corrected them. }\end{array}$ & O & O & O & O & O \\
\hline $\begin{array}{l}\text { If I can't do a problem, I keep trying } \\
\text { different ideas. }\end{array}$ & O & O & O & O & O \\
\hline
\end{tabular}

different ideas.

2. What is your perception towards use of TECHNOLOGY \& use of DIGITAL GAME to learn MATHEMATICS? *Mark only one oval per row.

\begin{tabular}{|c|c|c|c|c|c|}
\hline & $\begin{array}{l}\text { Strongly } \\
\text { Disagree }\end{array}$ & Disagree & $\begin{array}{l}\text { Not } \\
\text { Sure }\end{array}$ & Agree & $\begin{array}{c}\text { Strongly } \\
\text { Agree }\end{array}$ \\
\hline I am good at using computers. & O & $\bigcirc$ & $\bigcirc$ & $\bigcirc$ & O \\
\hline $\begin{array}{l}\text { I am good at using things like VCRs, DVDs, MP3s and } \\
\text { mobile phones. }\end{array}$ & O & O & O & O & O \\
\hline I can fix a lot of computer problems. & $\bigcirc$ & ○ & O & O & O \\
\hline $\begin{array}{l}\text { I am quick to learn new computer software needed for } \\
\text { school. }\end{array}$ & O & O & ○ & O & O \\
\hline I have a mathematical mind. & $\bigcirc$ & $\bigcirc$ & $\bigcirc$ & $\bigcirc$ & $\bigcirc$ \\
\hline I can get good results in mathematics. & $\bigcirc$ & O & $\mathrm{O}$ & $\mathrm{O}$ & $\mathrm{O}$ \\
\hline I know I can handle difficulties in mathematics. & $\mathrm{O}$ & O & O & ○ & $\bigcirc$ \\
\hline I am confident with mathematics. & O & $\bigcirc$ & O & ○ & $\mathrm{O}$ \\
\hline I am interested to learn new things in mathematics. & $\bigcirc$ & $\bigcirc$ & $\bigcirc$ & $\bigcirc$ & $\bigcirc$ \\
\hline In mathematics you get rewards for your effort. & $\mathrm{O}$ & $\mathrm{O}$ & O & O & O \\
\hline Learning mathematics is enjoyable. & $\mathrm{O}$ & $\mathrm{O}$ & O & $\mathrm{O}$ & $\mathrm{O}$ \\
\hline $\begin{array}{l}\text { I get a sense of satisfaction when I solve mathematics } \\
\text { problems. }\end{array}$ & $\mathrm{O}$ & $\mathrm{O}$ & O & O & $\mathrm{O}$ \\
\hline I like using digital game to learn mathematics. & $\bigcirc$ & $\bigcirc$ & $\bigcirc$ & $\bigcirc$ & $\bigcirc$ \\
\hline $\begin{array}{l}\text { Using digital game in mathematics is worth the extra } \\
\text { effort. }\end{array}$ & $\mathrm{O}$ & O & O & O & $\mathrm{O}$ \\
\hline Mathematics is more interesting when using digital game. & O & O & $\mathrm{O}$ & O & O \\
\hline Digital games can help me learn mathematics better. & O & O & O & 0 & 0 \\
\hline
\end{tabular}

The Mathematics and Technology Attitudes Scale (MTAS) adapted from Pierce et al. [6]. 